\title{
Medidas preventivas e orientação sobre Covid-19 para trabalhadores do Mercado do Produtor de Juazeiro (BA)
}

Preventive measures and guidance on Covid-19 for workers in Juazeiro Producer Market (BA)

DOS SANTOS, Maria Dionísia. Mestre em Administração.

IF Sertão-PE, Campus Petrolina. Rua Maria Luiza de Araújo Gomes Cabral, S/N, João de Deus -

Petrolina/PE -Brasil. CEP: 56316-686/ E-mail: dionisia.almeida@ifsertao-pe.edu.br

ALVES, Christiane Almeida de Macedo. Mestre em Enfermagem.

IF Sertão-PE, Campus Petrolina. Rua Maria Luiza de Araújo Gomes Cabral, S/N, João de Deus Petrolina/PE - Brasil. CEP: 56316-686 / E-mail: christiane.almeida@ifsertao-pe.edu.br

ASSUNÇÃO, Marhla Laiane de Brito. Mestre Ciências da Saúde e Biológica.

IF Sertão-PE, Campus Santa Maria da Boa Vista. BR 428, Km 90, Zona Rural - Santa Maria da Boa

Vista - Brasil. CEP: 56.380-000 / E-mail: marhla.assuncao@ifsertao-pe.edu.br

CABRAL. Natália Louise de Araújo. Mestre em Saúde Coletiva.

IF Sertão-PE, Campus Santa Maria da Boa Vista. BR 428, Km 90, Zona Rural - Santa Maria da Boa

Vista - Brasil. CEP: 56.380-000 / E-mail: natalia.louise@ifsertao-pe.edu.br

SANTO. Wyara da Silva do Espírito. Especialista em Enfermagem.

IF Sertão-PE, IF Sertão-PE, IF Sertão-PE, Campus Ouricuri. Ouricuri - Estrada do Tamboril, S/N -

Ouricuri - Brasil. CEP: 56200-000 / Email: wyara.espiritosanto@ifsertao-pe.edu.br

\section{RESUMO}

Este artigo trata-se de um relato de experiência de intervenção em saúde com os carrinheiros e vendedores ambulantes do Mercado do Produtor de Juazeiro-BA. O projeto foi estruturado por uma equipe interprofissional do Comitê de Enfrentamento à Covid-19 do IF Sertão-PE e teve como objetivo ajudar a proteger a saúde desses trabalhadores e seus familiares, bem como a interromper a cadeia de transmissão da Covid-19, atuando em duas linhas de prevenção: educação em saúde e distribuição de material de higienização (álcool em gel 70\% e sabonete líquido) e de máscaras artesanais, in loco, com a participação de 1.250 trabalhadores, de ambos os sexos. A experiência permitiu conhecer as peculiaridades do grupo, considerando a vulnerabilidade e invisibilidade social, diante da importância dos serviços essenciais prestados por esses trabalhadores; reforçou o papel social da instituição de educação; ratificou a necessidade da interprofissionalidade no combate à disseminação da Covid-19 e promoveu educação em saúde como estratégia mais importante para prevenção da transmissão do vírus.

Palavras-chave: Coronavírus, educação em saúde, prevenção.

\begin{abstract}
This article is an account of the experience of health intervention with the cartmen and street vendors of the Mercado do Produtor de Juazeiro-BA.The project was structured by an interprofessionalteam from the Coping Committee to Covid-19 of IF Sertão-PE and aimed to help protect the health of these workers and their families, as well as interrupting the Covid-19 transmission chain, acting in two lines of prevention: health guidelines and distribution of hygiene material (70\% gel alcohol and liquid soap) and hand-made masks, on site, with the participation of 1,250 workers, of both sexes. The experience allowed to know the peculiarities of the group, considering the vulnerability and social invisibility, given the importance of essential services provided by these workers; reinforce the social role of the educational institution; ratify the need for interprofessionality in combating the spread of Covid-19 and promoting health education as the most important strategy for preventing the transmission of the virus.
\end{abstract}

Key words: Coronavirus, health education, prevention. 


\section{Introdução}

A pandemia da Covid-19, decorrente da infecção pelo novo coronavírus (SARSCoV-2), gerou uma crise sanitária mundial desde a identificação dos primeiros casos

doença na China (AQUINO et al., 2020). Sua alta transmissibilidade e avanço do número de mortes ao redor do mundo levaram a World Health Organization (WHO), em tradução livre, Organização Mundial de Saúde (OMS), a declarar a Emergência de Saúde Pública de Importância Internacional (ESPIN) no dia 30 de janeiro de 2020 (WHO, 2020). O governo brasileiro decretou a ESPIN em 3 de fevereiro de 2020, orientando a articulação de ações nas três esferas governamentais para enfrentamento da pandemia (BRASIL, 2020a).

Diversas medidas foram adotadas e revisadas desde o decreto até os dias atuais. Incentivo ao distanciamento social, isolamento de casos, orientações quanto à etiqueta respiratória, higienização das mãos, uso de máscaras de tecido, além de outras decisões mais rígidas como fechamento de instituições de ensino, restrição e viagens, proibição de eventos e aglomerações, e, em casos extremos, o lockdown (AQUINO et al., 2020).

Apesar do fechamento de grande parte do comércio, os serviços considerados essenciais como clínicas, hospitais, farmácias e venda de alimentos continuaram em funcionamento. Nesse contexto, o exercício das atividades laborais, a depender das condições do ambiente de trabalho, pode ser uma fonte de exposição ao vírus, o que faz com que estratégias de enfrentamento devam ser realizadas para proteção dos trabalhadores dos serviços essenciais (FIHO et al., 2020).

Nessa conjuntura, estão as centrais de abastecimento de alimentos, locais em que o trabalho foi intensificado, em função do fechamento das feiras livres. Nesses ambientes, observa-se a participação de trabalhadores de diversas idades, homens e mulheres, que muitas vezes, encontram-se vulneráveis socialmente e expostos a condições inadequadas de trabalho (MASSON; MONTEIRO; VEDOVATO, 2015), situação vivenciada no Mercado do Produtor de Juazeiro/BA. O referido entreposto comercial é o quarto maior do Norte e Nordeste em volume e comercialização de hortigranjeiros do país, responsável pela circulação da produção agrícola que abastece várias regiões do país, inclusive os municípios de abrangência do Instituto Federal do Sertão Pernambucano (IF Sertão-PE).

Por sua relevância social, o Mercado foi considerado como estabelecimento essencial e não fechou suas atividades no período da pandemia. Conforme a Autarquia Municipal de Abastecimento (AMA), uma média de 10 mil pessoas frequentam o entreposto diariamente, um público diverso, inclusive, de várias partes do país, desde comerciantes, caminhoneiros, a trabalhadores informais que vivem em situação de vulnerabilidade social, além do público em geral que consome os produtos. No total, possui 1.360 boxes e, em média, 1.200 comerciantes e vários produtores. São cerca de 1000 carrinheiros e carregadores cadastrados, além de 250 vendedores ambulantes, de 25 a 50 anos de idade, a maioria homens e com renda semanal de $\mathrm{R} \$ 80,00$ a $\mathrm{R} \$ 100,00$, em situação de informalidade.

Os carrinheiros são profissionais que trabalham com carga, descarga e transporte de mercadorias (hortifrutigranjeiro) e utilizam como principal 
ferramenta de trabalho um carro em ferro tipo metalon (tubo de aço de carbono retangular), medindo aproximadamente dois metros de comprimento por um metro de largura, produzido em metalúrgicas e que se movem pela força da tração humana.

Considerando a importância social dos serviços prestados por esses trabalhadores para a manutenção da disponibilidade de alimentos durante a pandemia e entendendo o papel das instituições em retirar os vulneráveis da invisibilidade social, este estudo teve por objetivo relatar a experiência da distribuição de insumos de prevenção, cautela e redução de riscos de transmissão para o enfrentamento da Covid-19 junto aos carrinheiros e vendedores ambulantes do Mercado do Produtor de Juazeiro (BA).

\section{Material e métodos}

Trata-se de um relato de experiência decorrente de um projeto de intervenção de educação em saúde desenvolvido com os carrinheiros e vendedores ambulantes do Mercado do Produtor de Juazeiro (BA), o qual foi selecionado por meio do Edital n¹0/2020 do Instituto Federal do Sertão Pernambucano (IF Sertão$\mathrm{PE}$ ). O referido certame constituiu-se como um programa emergencial voltado ao fomento a Projetos de Pesquisa, Extensão e Inovação, destinado a iniciativas para enfrentamento da emergência de saúde pública decorrente da Covid-19, e custeado por meio de recurso extraorçamentário junto à Secretaria de Educação Profissional e Tecnológica (Setec)/MEC. Este projeto, enquadrado como Projeto de Extensão, foi estruturado por profissionais do Comitê de Enfrentamento à Covid-19 do IF Sertão-PE e contou com a participação de enfermeiras, nutricionista e uma jornalista.

Para o alcance do objetivo proposto, a pesquisa foi dividida em quatro fases, que culminaram em momentos de orientações de caráter educativo e de conscientização, bem como na distribuição de kits de prevenção da Covid-19, formado por uma bolsa tipo mochila/sacola com produtos de higiene das mãos (sabonete líquido e álcool a 70\% em gel) e duas máscaras de tecido (Figura 1).

$\mathrm{Na}$ Fase 1, foi realizada a articulação entre os pesquisadores do Comitê de Enfrentamento à Covid-19 do IF Sertão-PE e a coordenação do Mercado do Produtor, para identificação dos beneficiários e definição da logística de campo. Assim sendo, no dia 30/08/2020 ocorreu uma reunião com o Diretor Executivo da Autarquia Municipal de Abastecimento (AMA), bem como uma visita ao espaço do Mercado do Produtor. Nessa etapa, também se iniciou a cotação dos itens junto a empresas, a fim de buscar executar o projeto observando as melhores propostas para o IF Sertão-PE.

A Fase 2 consistiu na aquisição/compra dos sanitizantes (álcool e sabonete líquido), conforme menor valor especificado nas cotações, e na contratação de costureiras da região para produção de máscaras de tecido, em conformidade com as instruções dispostas na Nota Informativa $n^{\circ}$ 3/2020-CGGAP/DESF/SAPS/MS (BRASIL, 2020b), e para a confecção das bolsas tipo mochila/sacola, para que os beneficiários pudessem transportar adequadamente os insumos diariamente.

Posteriormente a essa etapa, foram montados os kits de prevenção da Covid19, composto por mochila/bolsa, máscaras, álcool em gel e sabonete líquido. Para tanto, primeiramente, foi realizado o fracionamento do sabonete líquido e do álcool em gel em frascos devidamente identificados e de quantidade/volume menor, de $100 \mathrm{ml}$ e $200 \mathrm{ml}$ (Fase 3). Optou-se pela compra dos produtos em embalagens de 
DOS SANTOS, M. D.; ALVES, C. A. M.; ASSUNÇÃO, M. L. B.; CABRAL N. L. A.; e SANTO, W. S. E.

Medidas preventivas e orientação sobre Covid-19 para trabalhadores do Mercado do Produtor de Juazeiro (BA)

maior quantidade (frascos de 5 litros) para prezar pelo princípio da economicidade e garantir a aquisição dos insumos, diante da escassez de mercado, em virtude da pandemia. Nas figuras 1 e 2 , a seguir, pode-se visualizar os itens/insumos que compõem os kits de prevenção.

Figura 1 - Insumos do kit de prevenção entregue aos trabalhadores

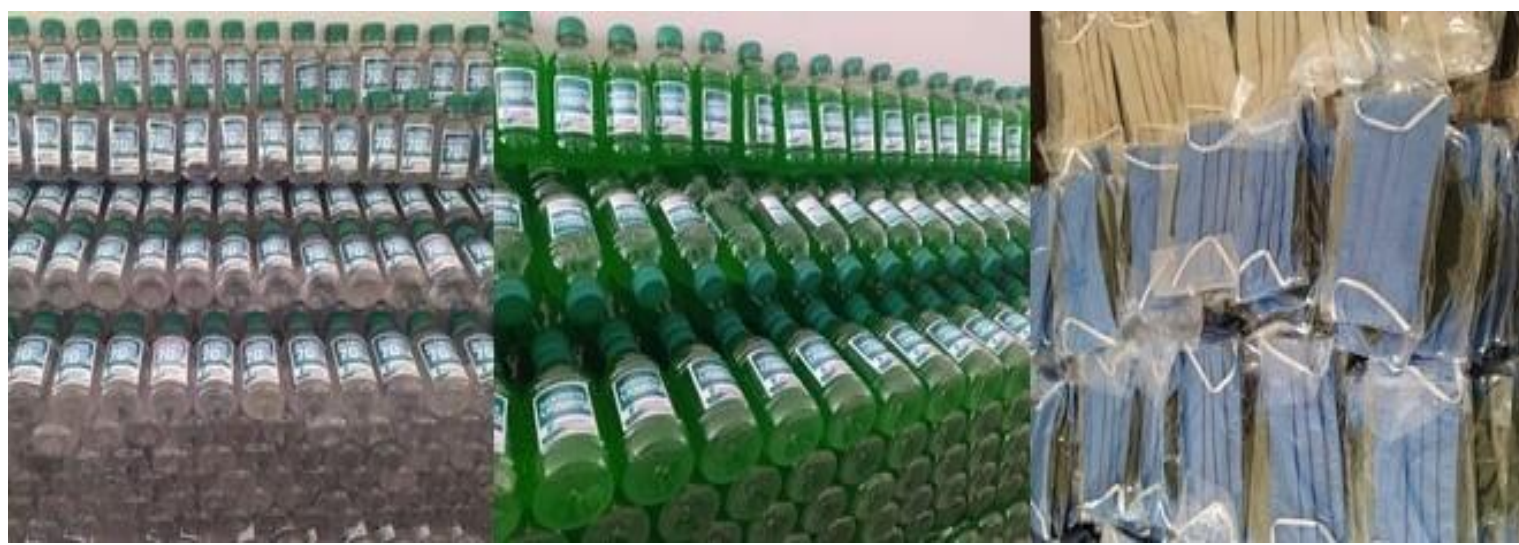

Fonte: Arquivo pessoal (2020).

Figura 2 - Kit completo entregue aos trabalhadores

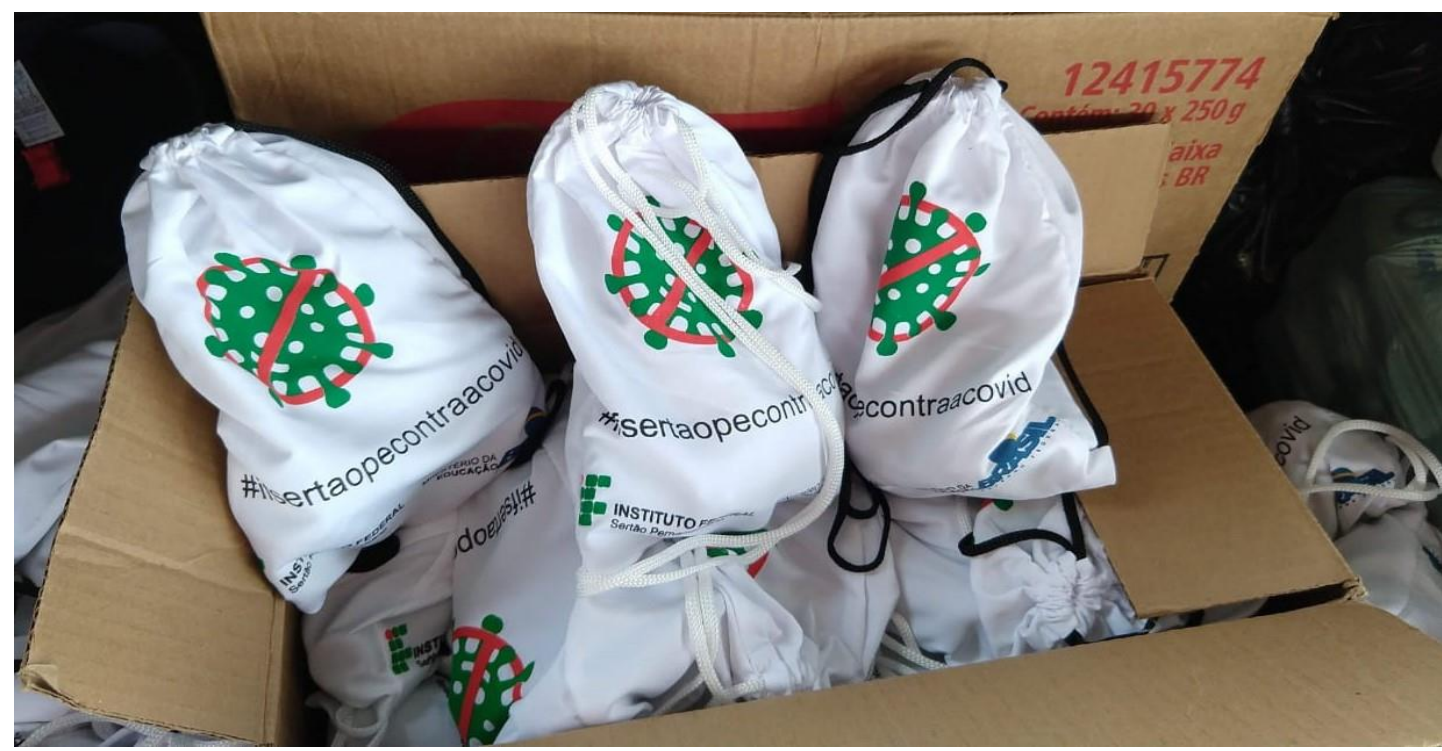

Fonte: Arquivo pessoal (2020).

$\mathrm{Na}$ última fase (Fase 4), ocorreu a distribuição dos kits, sendo também realizadas orientações verbais, reforçando as principais medidas de prevenção, pelos membros deste projeto, os quais participam do Comitê de Enfrentamento à Covid-19 da Instituição, e, portanto, apresentam capacidade técnica para prestar esclarecimentos acerca do tema. Nessa fase, também foi realizada a divulgação da ação junto aos meios de comunicação da região (televisão, blogs, site e rede social institucional) com o objetivo de ofertar visibilidade e reconhecimento aos trabalhadores, bem como fortalecer a imagem do IF Sertão-PE perante a sociedade 
como uma instituição que vai além do ensino na busca de contribuir com o fortalecimento do desenvolvimento social. Na figura 3 abaixo, apresenta-se um fluxograma que explicita as fases de planejamento e execução das atividades do projeto.

Figura 3 - Fluxograma do planejamento e execução das atividades de intervenção com os carrinheiros e vendedores ambulantes do Mercado do Produtor de Juazeiro BA.

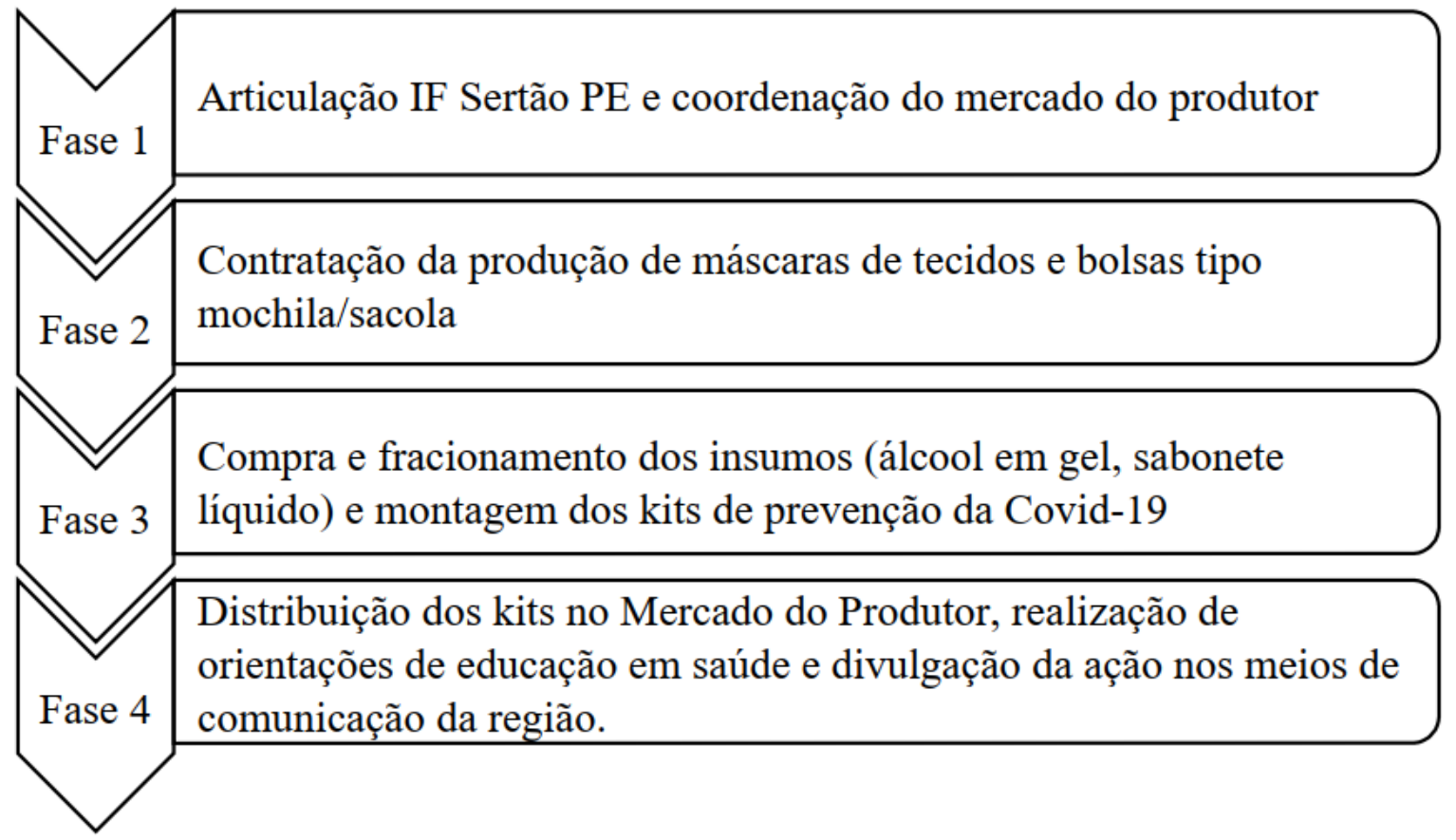

Fonte: Produção Autoras (2020).

\section{Resultados e discussão}

A intervenção de educação em saúde e distribuição dos kits de prevenção da Covid-19 no Mercado do Produtor de Juazeiro - BA aconteceram nos dias 09 e 28 de setembro de 2020, datas estas articuladas com o representante da associação dos carrinheiros junto ao Mercado do Produtor. A ação foi dividida em dois momentos com o principal objetivo de evitar a formação de aglomerações, conforme orientações da Organização Mundial da Saúde (OMS), referentes à mitigação da disseminação do novo coronavírus (WHO, 2020), bem como contemplar a totalidade de trabalhadores que estão organizados em regime de revezamento, alternando os dias de trabalho. A iniciativa atendeu cerca de 1.250 trabalhadores, em sua maioria homens, que foram beneficiados com o recebimento dos kits, além das orientações em saúde.

A equipe realizou a etapa de educação em saúde, por meio do fornecimento de orientações sobre o uso correto das máscaras, lavagem correta das mãos e uso do álcool em gel. Como estratégia para alcançar o público-alvo da pesquisa, foram recrutados os trabalhadores com farda, com o carro de mão (instrumento de trabalho) ou aqueles indicados pelo representante dos carrinheiros. Durante essa atividade pode-se também observar o quão relevante foi o trabalho de intervenção, devido à realidade que se apresentou aos participantes da pesquisa, a qual exibia 
inúmeros profissionais, comerciantes e transeuntes sem utilização de máscaras ou quaisquer outros itens de proteção contra a covid-19. Tal situação demonstrou o grau de vulnerabilidade à qual estavam submetidos os profissionais que desempenhavam seu trabalho no referido entreposto comercial e a pertinência do projeto de intervenção. Nas figuras 4 e 5, a seguir, estão registradas as entregas de kits a profissionais do Mercado do Produtor.

Figura 4 - Carrinheiro recebendo o kit de prevenção

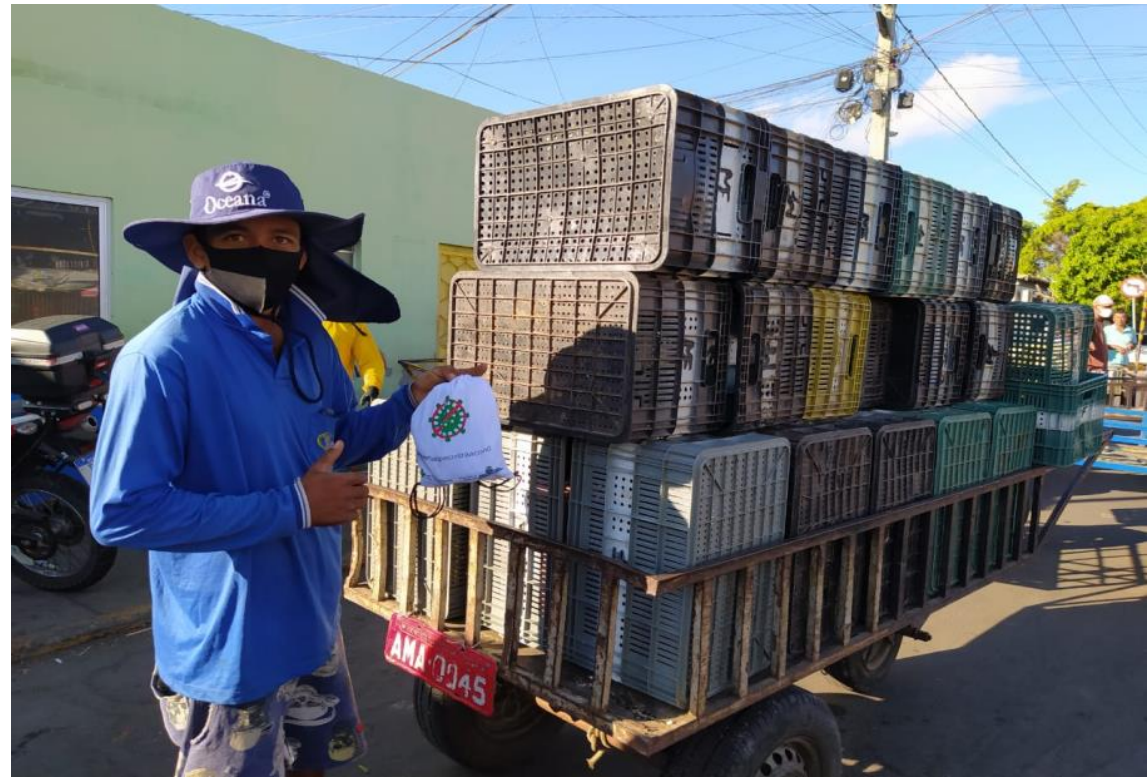

Fonte: Pesquisa direta (2021).

Figura 5 - Vendedor Ambulante recebendo orientações e o kit de prevenção

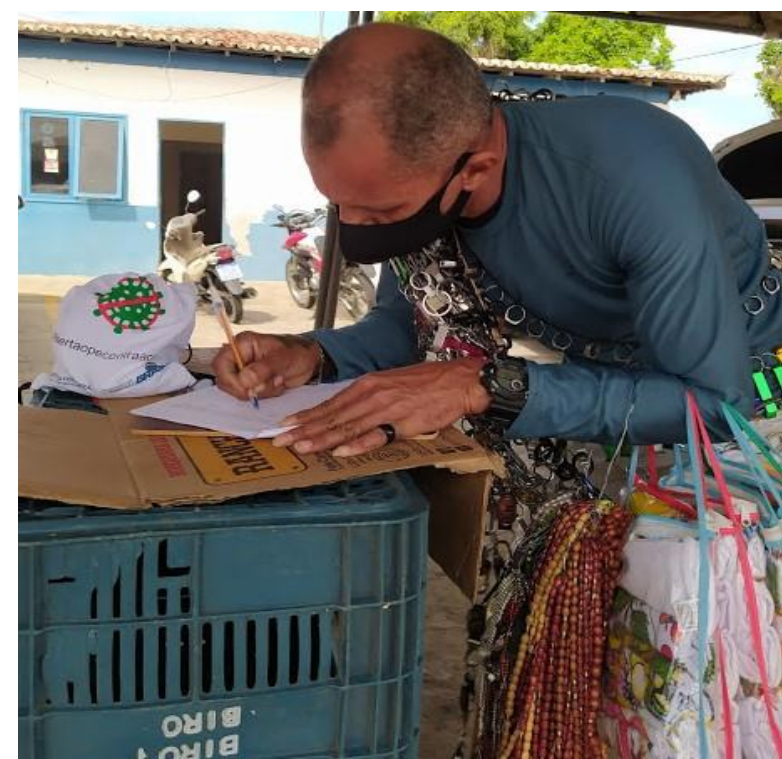

Fonte: Pesquisa direta (2021).

É oportuno registrar que, a princípio, o projeto contemplava a confecção de uma cartilha orientativa impressa para ser entregue aos profissionais em comento. Contudo, nas visitas para alinhamento com a coordenação do entreposto e os primeiros contatos com os trabalhadores, foi possível notar que, a maioria do 
público, era de baixa escolarização, muitos sem alfabetização, assim chegou-se a conclusão que a elaboração de material escrito e impresso não atenderia ao objetivo da comunicação e educação em saúde. Ademais, a equipe analisou que poderia ter o compartilhamento e a possibilidade de se tornar um meio de transmissão do vírus. Assim, sendo, no intuito de contemplar o público do projeto, bem como reduzir o risco de contaminação pelo novo coronavírus, optou-se pela orientação verbal, sem uso de cartilhas ou panfletos.

Nos dois momentos da realização da ação foi possível constatar que a escolha pela orientação verbal foi a mais acertada, uma vez que muitos dos trabalhadores não conseguiram assinar seus próprios nomes na lista de entrega. Assim, os registros nessas situações foram realizados pelos membros do Comitê.

Conforme dados informados pela AMA (aproximadamente 1.000 carrinheiros e 250 vendedores ambulantes) e o quantitativo de kits entregues, nota-se que o Projeto conseguiu atingir a quase totalidade dos trabalhadores, garantindo a esses profissionais insumos mínimos e máscaras para ajudarem a se prevenirem quanto aos riscos de infecção pela doença, uma vez que eles têm, diariamente, contato com comerciantes e caminhoneiros de várias partes do país.

Portanto, intervenções como esta ratificam o papel social das instituições de educação e a necessidade de intervenção interprofissional para o enfrentamento da Covid-19, tendo em vista que, diante do cenário de pandemia e com a necessidade da continuidade das ações por parte desses grupos de trabalhadores, torna-se uma condição sine qua non a realização de ações que visem garantir a segurança dessa força de trabalho.

Como já relatado neste texto, esta pesquisa contou com a participação de diferentes profissionais, constituindo uma multiplicidade de saberes, o que foi essencial para alcançar o objetivo almejado de realizar a educação em saúde. essa perspectiva, Ceccim (2018) traz que a interprofissionalidade favorece as trocas de informação e conhecimento, a cooperação solidária nos fazeres, a atenção corresponsável às necessidades em saúde para a construção de projetos terapêuticos e de promoção da saúde, o agir coletivo em território e a rede de laços afetivos que dá mais intensidade ao pertencimento a uma equipe.

Durante a pandemia de Covid-19, a educação em saúde, caracterizada pelo processo de construção de conhecimentos por parte da população, tem sido uma das estratégias mais importantes para prevenção da disseminação do vírus. Isso se torna especialmente relevante em um cenário de controvérsias entre as informações disseminadas pela mídia, redes sociais, pelos governos e organizações internacionais.

Dessa forma, orientar e ensinar corretamente a população sobre a identificação de sintomas da doença, promoção de práticas de cuidado e, principalmente, as formas de preveni-la, com foco na importância da adoção de práticas de etiqueta respiratória e higiene pessoal, é primordial para combater a pandemia (CECCON; SCHNEIDER, 2020).

Cabe ressaltar que, para garantir a eficácia das medidas preventivas, além da educação em saúde e da detenção do conhecimento sobre o assunto, é primordial que seja garantido o acesso aos insumos necessários à higienização. Com isso, destaca-se aqui a relevância desse tipo de trabalho, que disponibilizou os materiais para prevenção da Covid-19 neste público, além das orientações necessárias. Acrescenta-se que o projeto foi divulgado por vários meios de comunicação da região: TV, rádios e blogs, além das mídias oficiais da instituição. Assim sendo, também contribuiu para dar reconhecimento e visibilidade a esses 
trabalhadores que são peças chaves para o escoamento da produção agrícola local e que, portanto, exercem um papel de grande relevância social. Ademais, reforçou o papel social do IF Sertão-PE.

\section{Conclusões}

Diante de uma sociedade desigual, em que muitos estão em situações de vulnerabilidade social, a intervenção direta é necessária como medida urgente para o enfrentamento de situações de emergência social, como é o caso da pandemia, causada pelo novo coronavírus. É importante registrar que ações dessa natureza não diminuem a necessidade de implementação de políticas públicas efetivas e contínuas que busquem diminuir as grandes diferenças sociais, mas que intervenções como a deste Projeto contribuem diretamente para a garantia de direitos mínimos e a proteção de indivíduos que compõem as classes menos favorecidas economicamente. Ademais, comprovam que as instituições de educação, além do ensino, podem ajudar a solucionar problemas sociais por meio de suas ações de Pesquisa e Extensão. Foi o caso deste projeto que, diante da pandemia do coronavírus, uma equipe interprofissional viabilizou orientação em saúde e a distribuição de materiais de prevenção, a fim de ajudar a proteger um grupo de trabalhadores em situação de vulnerabilidade social e seus familiares, bem como a interromper a cadeia de transmissão da Covid-19.

\section{Referências}

AQUINO, E. M. L. et al. Social distancing measures to control the COVID-19 pandemic: Potential impacts and challenges in Brazil. Ciencia e Saude Coletiva, [s. l.], v. 25, p. 2423-2446, 2020.

BRASIL, M. da S. Portaria N ${ }^{\circ}$ 188, De 3 De Fevereiro De 2020. Diário Oficial da União, [s. l.], p. 7042, 2020. a.

BRASIL, M. da S. Nota Informativa No 3/2020-CGGAP/DESF/SAPS/MS. Ministerio da Saúde, [s. l.], p. 1-3, 2020. b. Disponível em: <https: / / www.saude.gov.br/images/pdf/2020/April/04/1586014047102-NotaInformativa.pdf>

CECCIM, R. B. Connections and boundaries of interprofessionality: Form and formation. Interface: Communication, Health, Education, [s. l.], v. 22, p. 17391749, 2018. Available at: https://doi.org/10.1590/1807-57622018.0477

CECCON, R. F.; SCHNEIDER, I. C. Tecnologias leves e educação em saúde no enfrentamento à pandemia da COVID-19. Pre- Print em analise, [s. l.], p. 19, 2020. Available at: https://doi.org/10.1017/CB09781107415324.004

FIHO, J. M. J. et al. A saúde do trabalhador e o enfrentamento da COVID-19. Revista Brasileira de Saúde Ocupacional, [s. l.], v. 45, p. 10-12, 2020.

MASSON, V. A.; MONTEIRO, M. I.; VEDOVATO, T. G. Trabalhadores da CEASA: fatores associados à fadiga e capacidade para o trabalho. Revista Brasileira de Enfermagem, [s. l.], v. 68, n. 3, p. 460-466, 2015. 
WHO. Getting your workplace ready for COVID-19. World Health Organization, [s. l.], n. March, p. 1-8, 2020. Disponível em: <www.WHO.int\%0Awww.WHO.int.> WORLD HEALTH ORGANIZATION. Statement on the first meeting of the International Health Regulations (2005) Emergency Committee regarding the outbreak of novel coronavirus (2019-nCoV). Geneva, [s. l.], 2020. Disponível em:

<https://www.who.int/news-room/detail/23-01-2020-statement-on-the-meetingof-the-international-health-regulations-(2005)-emergency-committee-regardingthe-outbreak-of-novel-coronavirus-(2019-ncov)> 